\title{
Ángela García-Alaminos*
}

\section{LA HUELLA SOCIOECONÓMICA DEL COMERCIO INTERNACIONAL}

En un contexto en el que la búsqueda de un desarrollo sostenible integral se ha convertido en una necesidad apremiante, el rol del comercio internacional resulta controvertido. Por esa razón, es necesario evaluar cuantitativamente en qué medida las redes comerciales globales son responsables de la desigual distribución de rentas y empleo. Para ello, en este artículo se realiza un análisis input-output multirregional incluyendo factores de carácter socioeconómico con el fin de rastrear impactos y responsabilidades a través del cálculo de huellas. Los resultados manifiestan la dualidad del comercio internacional como generador de rentas para regiones desfavorecidas y como canal de distribución no equitativa.

Palabras clave: sostenibilidad, modelo input-output multirregional, distribución de rentas, cualificación del factor trabajo.

Clasificación JEL: C67, F63, J24, O15.

\section{Desarrollo sostenible y comercio} internacional

El desarrollo sostenible es quizás el mayor reto al que se enfrenta la humanidad actualmente. La necesidad de evaluar hacia dónde lleva la senda de crecimiento comienza a fraguarse en el Siglo XVIII con las teorías maltusianas sobre agotamiento de recursos, pero es en 1987 cuando surge el concepto moderno de desarrollo sostenible con la publicación del Informe Brundtland (Brundtland y Khalid, 1987). De este modo, se supera la acepción tradicional de desarrollo como

\footnotetext{
* Global Energy and Environmental Economics Analysis Research Group, Facultad de Ciencias Económicas y Empresariales, Albacete. Universidad de Castilla-La Mancha,

Versión de 26 de febrero de 2017.
}

mero crecimiento económico, pasando a considerarse el avance social y la protección medioambiental como elementos indispensables para materializar el desarrollo económico de forma justa y con garantías de futuro.

Ante el reto de avanzar hacia un desarrollo sostenible integral, la Organización de Naciones Unidas (ONU en adelante) insta a la comunidad internacional a intensificar sus esfuerzos para limar las desigualdades, luchar contra el cambio climático y garantizar un nivel digno de desarrollo y bienestar para toda la humanidad a través de los Objetivos de Desarrollo Sostenible incluidos dentro de la Agenda 2030 para el Desarrollo Sostenible (UN, 2015a). Dentro de este marco de acción, la institución aborda explícitamente el papel de las redes de producción y consumo globales mediante la meta de promover un sistema de comercio internacional no discriminatorio y equitativo en 
el que los países en desarrollo tengan un protagonismo creciente (UN, 2015b).

A pesar de las acciones propuestas por la ONU, el camino hacia un desarrollo sostenible global presenta ciertos escollos en un contexto en el que la creciente complejidad de las redes comerciales hace cada vez más arduo el rastreo de las responsabilidades e impactos de las transacciones. El comercio internacional se presenta en la Agenda 2030 como una vía para lograr la alianza interregional necesaria para erradicar las desigualdades, la pobreza o la devastación medioambiental (UN, 2013) e, indudablemente, la globalización y el comercio internacional han generado numerosas oportunidades para países tradicionalmente desfavorecidos (WTO, 2017). Sin embargo, ese mismo fenómeno de interconexión de las cadenas de valor globales también ha desencadenado una cierta tendencia a la sobreexplotación de recursos humanos y medioambientales, un crecimiento acelerado y desigual que se muestra insostenible y una separación entre producción y consumo que diluye la concienciación sobre los problemas globales.

Dada la dualidad del comercio internacional, su actual contribución al desarrollo en sentido amplio a nivel mundial es un aspecto controvertido. La hipótesis de partida de este trabajo deriva directamente de los argumentos propuestos por la ONU: una mayor apertura de los mercados desarrollados hacia productos de países en vías de desarrollo es positiva para alcanzar el desarrollo sostenible global (UN, 2017). El objetivo de este artículo es profundizar en dicha idea poniendo el foco en los impactos económicos y laborales desencadenados por el comercio internacional. De este modo, se pretenden analizar los patrones derivados de las redes comerciales globales a través del cálculo de huellas de distribución de la renta y de trabajo por nivel de cualificación para el año 2011. El cálculo de huellas se sustenta en un modelo input-output multirregional (MRIO en adelante), considerado como una de las mejores herramientas para analizar con profundidad las implicaciones de las complejas cadenas globales de la producción (Wiedmann, 2016). Empleando una metodología que permite combinar información sectorial y regional y que proporciona una amplia riqueza en detalles, la principal contribución del análisis planteado es precisamente ahondar en los patrones latentes que emanan de las complejas cadenas de producción y consumo globales y que pueden afectar directa o indirectamente a la consecución del ideal de desarrollo que las instituciones supranacionales promueven.

\section{Revisión de la literatura:}

desarrollo sostenible e impactos del comercio internacional

La vinculación entre comercio internacional y desarrollo sostenible es un tema de actualidad que la literatura ha abordado bajo diversas perspectivas. La idea institucional de que el comercio internacional genera ganancias para los estados participantes, y en concreto para países en desarrollo (IMF, 2006; WTO, 2017), parece haberse desmitificado al considerar aspectos que trascienden las puras ganancias económicas en términos agregados. De acuerdo a Milanovic (2014), al comparar los determinantes actuales de la desigualdad global con los de finales del Siglo XIX, se observa que el elemento de ubicación (desigualdad internacional, es decir, el hecho de que la renta de una persona esté condicionada por el país en el que reside y trabaja) ha ganado un peso considerable en detrimento del elemento de clase (desigualdad intranacional o diferencias de rentas entre los diferentes estratos socioeconómicos de un mismo país), lo que sitúa a la globalización en el punto de mira como uno de los posibles motores de este distanciamiento entre naciones. Organismos como la OCDE son conscientes de la incapacidad del comercio por sí solo de generar las mejoras que se esperan en países en desarrollo (OCDE, 2017), de modo que la literatura ha ahondado en esta problemática desde diversos puntos de vista complementarios.

Bajo una óptica institucional, trabajos como el de Mosley y Uno (2007) prueban que los derechos del trabajador guardan una correlación negativa con el 
grado de apertura del país en cuestión, lo que apoya la idea de que una inclusión honesta de países emergentes en las redes de comercio internacional requiere la intervención de instituciones internacionales para evitar posibles tendencias perniciosas. No obstante, para que la acción internacional sea efectiva y las pautas comerciales perniciosas sean extinguidas, resulta imprescindible conseguir una buena gobernanza que articule niveles subnacional, nacional y supranacional y que permita un desarrollo sincrónico a nivel económico e institucional (Ramos y Sota, 2014).

Desde una perspectiva en la que se consideran simultáneamente los papeles de consumidor y productor como causantes de ineficiencias en el comercio internacional, la metodología input-output se ha revelado como una de las herramientas más potentes (Wiedmann, 2016). Su capacidad de cuantificar impactos directos e indirectos a lo largo de la cadena de valor permite revelar la dicotomía entre crecimiento económico y desarrollo sostenible en un contexto internacional. Este tipo de trabajos pueden dividirse en dos grandes bloques: aquellos que determinan impactos medioambientales y los orientados a impactos socioeconómicos, ambos relacionados mediante trabajos transversales que combinan los efectos de ambas externalidades.

Comenzando por la vertiente medioambiental, trabajos como el de Arce (2014) revisan las diversas evidencias empíricas existentes en torno a los impactos medioambientales negativos derivados del creciente comercio internacional, como la denominada hipótesis del refugio de emisiones (Copeland y Taylor, 2004), la cual establece que las industrias contaminantes tienden a ser deslocalizadas a regiones con una legislación medioambiental laxa. Al considerar esta hipótesis en un contexto relativo a salud y desarrollo social, surgen estudios transversales que aúnan lo medioambiental con lo social combinando los efectos de ambas externalidades. Vargas y Dietzenbacher (2012) proponen que ciertos países emergentes presentan como fuente de ventaja comparativa una mayor tolerancia hacia el deterioro de la salud de sus ciudadanos, de modo que su apertura económica se sustenta en la exportación de bienes cuya producción es intensiva en emisiones a pesar de que haya una clara correlación con el deterioro de la salud de su población. Adicionalmente, a mayor nivel de integración económica de un país en el comercio internacional, mayor será el nivel de emisiones de dióxido de azufre $\left(\mathrm{SO}_{2}\right)^{1}$. La mortalidad asociada a ese agente contaminante dependerá de los mecanismos de compensación de que disponga el país afectado, los cuales son más efectivos a mayor grado de desarrollo e integración (Prell et al., 2015)

Pasando a la aplicación del cálculo de huellas a la faceta puramente socioeconómica del desarrollo, el marco desarrollado por Gómez-Paredes et al. (2015) expone la idoneidad de esta metodología para evaluar aspectos laborales detrás de las complejas cadenas de producción internacionales existentes actualmente. La posibilidad de utilizar esta metodología para medir diversos tipos de impactos y su capacidad de implementar diferentes criterios de atribución de responsabilidades hacen de ella una herramienta fundamental para analizar la sostenibilidad del comercio internacional. No obstante, el análisis de impactos sociales mediante el cálculo de huellas es un campo de estudio emergente, con numerosas posibilidades, pero un desarrollo aún incipiente si se compara con la vertiente medioambiental debido a la carencia de datos fiables. Algunos de los principales trabajos existentes han probado que en la actualidad se dan elevados flujos de trabajo precario asociado a los bienes procedentes de países en desarrollo importados por las naciones ricas. El consumo masivo en el primer mundo de bienes no duraderos producidos con un coste extremadamente bajo ha desencadenado una carrera para reducir tiempos y costes y aumentar la producción en países emergentes. Esta denominada race to the bottom (Alsamawi et al., 2014) ha originado un crecimiento mal estructurado en regiones de reciente apertura internacional que emplean

\footnotetext{
$1 \mathrm{El} \mathrm{SO}_{2}$ es uno de los gases contaminantes directos más importantes. A diferencia del dióxido de carbono $\left(\mathrm{CO}_{2}\right)$, el metano $\left(\mathrm{CH}_{4}\right)$ o los nitratos $\left(\mathrm{NO}_{x}\right)$, el $\mathrm{SO}_{2}$ no es un gas efecto invernadero sino un contaminante de carácter directo con implicaciones a nivel local, siendo especialmente relevantes sus efectos perniciosos sobre la salud.
} 
la precariedad y desigualdad como principal fuente de ventaja competitiva (Simas et al., 2014). De este modo, podría pensarse que el comercio internacional no solo no contribuye a limar la desigualdad, sino que la fomenta. No obstante, tanto la literatura como las instituciones inciden en que la apertura comercial puede resultar muy positiva para regiones emergentes si se combina con políticas orientadas a reducir la disparidad salarial, mejorar el capital humano y la infraestructura y facilitar el acceso a la educación (Simas et al., 2014; OECD, 2017).

Sin embargo, la problemática de implementar políticas adecuadas para lograr ciertos objetivos sin comprometer la consecución de otros a nivel internacional es un tema de especial interés, dado que los programas para la consecución del desarrollo sostenible en una región pueden generar impactos indeseados en otros lugares (Monsalve et al., 2016). En un contexto globalizado como el actual, las políticas de desarrollo pueden tener un alcance global como consecuencia de las redes comerciales internacionales, de modo que a la hora de diseñar dichos programas deben contemplarse las cadenas de producción y consumo de forma integral, lo cual resulta verdaderamente complejo.

En definitiva, todas estas ideas permiten apreciar que el papel del comercio internacional en la senda hacia un desarrollo sostenible integral (económico, social y medioambiental) es ciertamente controvertido. Si a esto se le añade la dificultad de implementar políticas eficaces orientadas al desarrollo, resulta esencial desentrañar las ramificaciones y múltiples impactos de las cadenas de producción y consumo para poder corregir las posibles ineficiencias derivadas del comercio internacional.

\section{Metodología y fuentes de datos:} trazando impactos globales

\section{Modelo input-output multirregional}

El análisis input-output es un marco teórico desarrollado por W. Leontief con el propósito de analizar los flujos de productos y rentas entre los agentes de una economía. Esta metodología divide los flujos comerciales en dos categorías: comercio de bienes intermedios adquiridos por industrias específicas y comercio de bienes finales destinados a abastecer directamente la demanda final. La idoneidad de esta técnica estriba en su capacidad de cuantificar impactos directos e indirectos a lo largo de la cadena de valor en sistemas económicos complejos, pudiendo así determinar responsabilidades asociadas a unos ciertos niveles de producción y demanda final (Gómez-Paredes et al., 2015; Miller y Blair, 2009).

En este estudio se va a emplear un modelo input-output multirregional. Siguiendo a Miller y Blair (2009), la Expresión [1] muestra la ecuación extendida del modelo input-output en formato matricial.

$$
G=\hat{F} \cdot(1-A)^{-1} \hat{Y}
$$

Donde:

- $\hat{Y}$ es la matriz de demanda final. Cada elemento muestra la demanda final realizada por una cierta región de bienes y servicios producidos por un determinado sector ubicado en una determinada región ${ }^{2}$.

- A denota la matriz de coeficientes técnicos, calculada directamente a partir de la información disponible en las Tablas input-output (TIO en adelante) disponibles en diversas bases de datos. Cada elemento $\alpha_{i j}^{r s}$ incluido en $A$ representa el montante en términos monetarios de inputs procedentes del sector $i$ de la región $r$ (filas) que el sector $j$ en la región $s$ (columnas) requiere para fabricar una unidad monetaria (um) de producto.

Junto a la matriz identidad (I), $A$ da lugar a la inversa de Leontief, denotada por $L$ y definida en la Expresión [2].

$$
L=(I-A)^{-1}
$$

\footnotetext{
2 La matriz de demanda final puede considerarse particionada como una cuadrícula de vectores columna, cada uno de los cuales representa la demanda final realizada por una cierta región de bienes y servicios producidos en todos los sectores de una determinada región de origen. Si cada uno de esos vectores columna se despliega en forma de matriz diagonal, la introducción en el modelo de la matriz que aúna todas esas diagonales $(\hat{Y})$ permite interpretar mejor los resultados de salida del modelo.
} 
La inversa de Leontief actúa como multiplicador keynesiano del output multisectorial y multirregional, puesto que permite calcular en qué medida ha de aumentar el output de toda la economía (cuantificando tanto efectos directos como indirectos) para atender un cierto incremento de la demanda final. Un análisis por columnas de $L$ lleva al concepto de sector verticalmente integrado, el cual se define como el sector virtual que recoge toda la producción necesaria en el conjunto de sectores y regiones para cubrir el aumento unitario de demanda final del bien o servicio fabricado por un cierto sector en una determinada región.

El modelo input-output permite premultiplicar la inversa de Leontief por una matriz diagonal $-\hat{F}$ en la Expresión [1] — que represente los requerimientos por unidad de output para cada región y sector de cierto factor implicado en el proceso productivo. De este modo se obtiene un multiplicador que aporta información adicional al ser introducido en el modelo. El factor seleccionado debe cumplir la condición de aumentar proporcionalmente con la producción, siendo algunos de los más usuales el empleo, las emisiones, la energía, etc.

Con todos estos elementos, el resultado del modelo ${ }^{3}$ -matriz denotada por $G$ en la Expresión [1] — recoge los impactos directos e indirectos asociados al factor elegido. Cada fila de $G$ muestra la producción de un sector determinado en una región concreta necesaria para cubrir directa o indirectamente la demanda final de bienes en general. Desde el punto de vista del cálculo de responsabilidades este montante se imputaría como responsabilidad del productor. Cada columna de $G$ representa la producción necesaria (directa o indirectamente) en el conjunto de sectores de todas las regiones para abastecer la demanda final del bien fabricado por la rama en cuestión en la región correspondiente (sector

\footnotetext{
3 En cuanto a los aspectos técnicos del modelo, este ha sido implementado con el software Matlab (MathWorks Inc., 2016) mediante un código de elaboración propia. La necesidad de recurrir a un programa de cálculo numérico estriba en el tamaño de las matrices manejadas: la complejidad de calcular inversas de Leontief de grandes dimensiones con otras herramientas es evidente y el uso de este software permite ahorrar tiempo y ganar precisión respecto a otros métodos.
}

verticalmente integrado). Esta lectura correspondería a la responsabilidad del consumidor o huella, concepto de uso habitual en la literatura input-output (Arto et al., 2015; Gómez-Paredes et al., 2016; Monsalve et al., 2016; Simas et al., 2015).

Lo interesante de este tipo de análisis es que las dos ópticas mencionadas — productor y consumidor- conducen a una atribución de responsabilidades distinta. La globalización y el elevado grado de apertura internacional permiten una fácil separación de producción y consumo, de modo que el impacto de la demanda final de un país se dispersa más allá de las fronteras nacionales cuando se emplean criterios alternativos al de producción. La aplicación del modelo input-output en este trabajo pasa por emplear factores de carácter socioeconómico relacionados con el empleo, con lo que podrá evaluarse cómo el consumo en cada país genera a lo largo del mundo ocupaciones de distintas características y calidad a través del comercio internacional y las cadenas globales de la producción.

\section{Base de datos multirregional}

La base de datos multirregional en la que se apoya el modelo input-output implementado es la World Input-Output Database (WIOD) en su versión de 2011 (Timmer et al., 2015; Timmer et al., 2016). Esta fuente proporciona una serie anual de TIO multirregionales, de las cuales se ha empleado la correspondiente al año 2011. Adicionalmente, la WIOD publica datos sobre los factores empleados en los procesos productivos, los cuales son susceptibles de ser introducidos en un modelo input-output para determinar impactos específicos.

El formato estándar de partida de dichas TIO presenta cuantías expresadas en millones de dólares corrientes para 35 sectores productivos y 41 regiones: 27 países de la Unión Europea y 13 países no europeos de especial relevancia, los cuales supusieron más del 85 por 100 del PIB mundial en 2008, más una gran región representativa de las zonas restantes denominada «resto del mundo». En este estudio se han 
agregado los datos a 18 regiones y 14 sectores derivados de la clasificación ISIC-Rev. 3. No obstante, se ha trabajado de forma paralela con una agregación más compacta (7 grandes bloques regionales y 14 sectores) con el fin de representar ciertos resultados de un modo más sintético. Las dos agregaciones regionales propuestas se detallan en el Cuadro A1 y las equivalencias sectoriales figuran en el Cuadro $\mathrm{A} 2$, todas ellas incluidas en el Anexo I.

\section{Indicadores seleccionados para cuantificar impactos socioeconómicos}

Una de las dificultades que abordar a la hora de relacionar desarrollo sostenible y comercio internacional mediante un modelo MRIO es la selección de indicadores que actúen como factores. Por una parte, deben ser relevantes y aportar información concreta en relación al ideal de desarrollo institucionalmente aceptado, y por otra parte deben proceder de fuentes fiables $y$ tener un nivel de detalle elevado tanto a nivel regional como sectorial.

La base de datos WIOD proporciona diversas cuentas satélite de carácter socioeconómico y medioambiental que detallan el uso de factores en los procesos productivos de cada región y sector. Concretamente, se han empleado las cuentas de carácter socioeconómico del año 2011, de las que se han extraído nueve indicadores con la finalidad de generar cinco factores susceptibles de ser introducidos en el modelo MRIO como se mostró en la Expresión [1]. Todos ellos se muestran en el Cuadro 1 clasificados en dos grupos de factores más un grupo de variables auxiliares.

El primer grupo de factores (denominado distribución de rentas en el Cuadro 1) está compuesto por dos indicadores de carácter económico cuya finalidad es trazar cómo se distribuye la renta entre los factores capital y trabajo. De este modo, podrá determinarse si la pobreza enquistada en ciertas regiones puede ser consecuencia de una inadecuada distribución de la renta entre factores productivos y si la desigualdad interregional puede estar motivada por una fuga de rentas generadas en países desfavorecidos hacia países prósperos. La Organización de Naciones Unidas (UN, 2015b) manifiesta abiertamente que la desigualdad en la distribución de los ingresos favorece la exclusión social, económica y política. Se trata de un problema alarmante, especialmente cuando se evalúan las diferencias entre países desarrollados y en desarrollo, de ahí la necesidad de evaluar el grado de implicación del comercio internacional en el fenómeno de distribución de rentas. A través de estos indicadores se espera ahondar en la controvertida cuestión de quiénes son los principales beneficiarios de la apertura de mercados desarrollados a países emergentes.

Los tres indicadores que conforman el Grupo 2 (denominado «cualificación en el empleo» en el Cuadro 1) aluden a las horas trabajadas por empleados de cualificación alta, media y baja. También han sido extraídos de WIOD, pero en este caso de forma indirecta: como indica la Expresión [3], se han multiplicado las horas de trabajo totales por las participaciones por cualificación sobre el total de horas trabajadas ${ }^{4}$.

$$
H_{i}=P_{i} \cdot H ; H=\Sigma_{i=1}^{3} H_{i}=H H+M H+L H
$$

Siendo: i=Alta $(H)$, Media $(M)$, Baja $(L)$.

El análisis de los tres indicadores del Grupo 2 permitirá trazar flujos de empleo cuyo sentido podría depender de la cualificación de los trabajadores. Se espera que los resultados permitan diferenciar regiones en las que se concentra el uso de empleo de baja cualificación como factor productivo - segmento en el que suelen darse incidencias de trabajo precario más elevadas (ILO, 2012; Simas et al., 2014)— frente a regiones en las que la mano de obra de baja cualificación se importa incorporada a los bienes.

\footnotetext{
4 Nota: ver códigos de notación para variables auxiliares mostrados en el Cuadro 1.
} 


\section{CUADRO 1}

INDICADORES SELECCIONADOS A MODO DE FACTORES PARA EL MODELO MRIO

\begin{tabular}{|c|c|c|c|c|c|}
\hline Grupo & Indicador & Cod. & Descripción & Unidades & Fuente principal \\
\hline \multirow{2}{*}{ G1. Distribución de rentas } & $\begin{array}{l}\text { Remuneración } \\
\text { del trabajo }{ }^{1}\end{array}$ & $L A B$ & $\begin{array}{l}\text { Rentas obtenidas por el factor } \\
\text { trabajo. }\end{array}$ & $\begin{array}{l}\text { Millones } \\
\text { de dólares }\end{array}$ & $\begin{array}{l}\text { WIOD } \\
\text { versión } 2011\end{array}$ \\
\hline & $\begin{array}{l}\text { Remuneración } \\
\text { del capital }{ }^{3}\end{array}$ & $C A P$ & $\begin{array}{l}\text { Residuo resultante al detraer } \\
\text { del valor añadido bruto la } \\
\text { remuneración del trabajo. }\end{array}$ & $\begin{array}{l}\text { Millones } \\
\text { de dólares }\end{array}$ & $\begin{array}{l}\text { WIOD } \\
\text { versión } 2011\end{array}$ \\
\hline \multirow{4}{*}{ Indicadores auxiliares² } & Horas de trabajo & $H$ & $\begin{array}{l}\text { Horas trabajadas por todo } \\
\text { tipo de trabajadores }{ }^{4}\end{array}$ & $\begin{array}{l}\text { Millones } \\
\text { de horas }\end{array}$ & $\begin{array}{l}\text { WIOD } \\
\text { versión } 2011\end{array}$ \\
\hline & \multirow{3}{*}{$\begin{array}{l}\text { Participación por } \\
\text { cualificación } \\
\text { (alta/media/baja) } \\
\text { sobre el total } \\
\text { de horas trabajadas }\end{array}$} & $H P$ & $\begin{array}{l}\text { Horas trabajadas por empleados } \\
\text { de cualificación alta sobre el } \\
\text { total de horas trabajadas. }\end{array}$ & & \\
\hline & & $M P$ & $\begin{array}{l}\text { Horas trabajadas por empleados } \\
\text { de cualificación media sobre } \\
\text { el total de horas trabajadas. }\end{array}$ & Porcentaje & $\begin{array}{l}\text { WIOD } \\
\text { versión } 2011\end{array}$ \\
\hline & & $L P$ & $\begin{array}{l}\text { Horas trabajadas por empleados } \\
\text { de cualificación baja sobre } \\
\text { el total de horas trabajadas. }\end{array}$ & & \\
\hline \multirow{3}{*}{ G2. Cualificación laboral } & & $H H$ & $\begin{array}{l}\text { Horas trabajadas por } \\
\text { empleados de cualificación alta. }\end{array}$ & & \multirow{3}{*}{$\begin{array}{l}\text { Indicador } \\
\text { calculado en } \\
\text { base a datos } \\
\text { de WIOD }\end{array}$} \\
\hline & $\begin{array}{l}\text { Horas de trabajo } \\
\text { por cualificación } \\
\text { (alta/media/baja) }\end{array}$ & $M H$ & $\begin{array}{l}\text { Horas trabajadas por empleados } \\
\text { de cualificación media. }\end{array}$ & $\begin{array}{l}\text { Millones } \\
\text { de horas }\end{array}$ & \\
\hline & & $L H$ & $\begin{array}{l}\text { Horas trabajadas por empleados } \\
\text { de cualificación baja. }\end{array}$ & & \\
\hline
\end{tabular}

NOTAS: ${ }^{1}$ Incluye rentas de asalariados, trabajadores por cuenta propia y trabajadores familiares. ${ }^{2}$ WIOD proporciona estos indicadores en millones de moneda nacional, de modo que han sido convertidos a dólares estadounidenses con los tipos de cambio proporcionados por la misma fuente. ${ }^{3}$ Se considera capital en sentido amplio: capital físico, tierra (incluyendo recursos minerales), capital financiero y capital intangible. ${ }^{4}$ Incluye horas trabajadas por autónomos y trabajadores familiares si están disponibles, pero en gran parte de los casos refleja exclusivamente trabajadores por cuenta ajena. ${ }^{5}$ Método de cálculo descrito en la Expresión (3).

FUENTE: Elaboración propia según datos de WIOD.

Es necesario destacar que en varias regiones algunos de los indicadores de los grupos 1 y 2 no estaban disponibles para el año 2011 en WIOD, de modo que se ha extrapolado de acuerdo a los valores disponibles para 2009. Para las variables del Grupo 1, la extrapolación se ha realizado multiplicando el porcentaje de remuneración del capital o trabajo sobre el total del Valor
Añadido (VA en adelante) por el VA de los años 2010 y 2011. Para las variables auxiliares de las que surgen los indicadores del Grupo 2, la extrapolación se ha hecho siguiendo el índice de crecimiento anual para variables expresadas en términos absolutos y suponiendo el mismo valor que en 2009 en el caso de variables expresadas en términos porcentuales. 


\section{Impactos socioeconómicos del comercio internacional}

\section{Distribución de rentas}

Cuantificar qué parte del VA se destina a remunerar el capital y qué parte va dirigida a remunerar el factor trabajo permite caracterizar la distribución de la renta en una economía. A través del análisis de estas variables en términos de huella puede evaluarse si la demanda final de una región se sustenta en bienes y servicios intensivos en capital o en trabajo, así como aportar alguna idea preliminar sobre la equidad en la distribución de la riqueza tras la huella.

El Gráfico 1 muestra la huella de distribución de la renta de cada región en términos absolutos, así como la participación relativa -en términos porcentualesde cada uno de sus dos componentes sobre el total de VA. Las regiones con una huella de valor añadido más elevada en 2011 son de dos tipos: zonas con una alta demanda final debido a su gran tamaño (China o RoW) o regiones desarrolladas que demandan productos de alto valor añadido como bienes intensivos en capital o intensivos en mano de obra altamente remunerada (Estados Unidos o Europa del Norte). En lo que a remuneración del capital se refiere, las regiones con mayor huella son, por orden de importancia ${ }^{5}$, Estados Unidos, China y Europa del Norte. En cuanto a la remuneración del trabajo, las regiones más relevantes en términos absolutos son todas ellas desarrolladas (Estados Unidos, Europa del Norte y Japón). China, pese a su gran tamaño, queda relegada al cuarto puesto en lo que a huella de remuneración del trabajo respecta.

En términos relativos, solo tres regiones presentan una huella de remuneración del capital superior a la de remuneración del trabajo: Indonesia, México y Turquía,

\footnotetext{
5 En el análisis jerárquico de regiones se ha omitido «Resto del Mundo« dado que no representa una tipología concreta de país. Se trata de un compendio de regiones muy dispares y con distintos grados de desarrollo, de modo que su interpretación no aporta conclusiones claras.
}

todos ellos países emergentes próximos tanto a mercados desarrollados como en desarrollo. Detrás de estos porcentajes se esconde un crecimiento del tejido productivo nutrido con bienes intensivos en capital, ya sea de origen doméstico o procedentes de socios más desarrollados (China y Japón en el caso de Indonesia, Estados Unidos en el caso de México o la UE en el caso de Turquía) junto a un abastecimiento del consumo final de los hogares (mayoritariamente con poder adquisitivo medio-bajo) con bienes producidos con trabajo de baja remuneración, ya sea procedente de la propia región o de zonas limítrofes que ofrecen mano de obra barata. Esta situación genera dudas acerca de la adecuación del modelo de crecimiento de zonas emergentes de cara a lograr un desarrollo sostenible. Un crecimiento que prima especialmente la remuneración del capital en lugar de la del trabajo no parece contribuir a erradicar la desigualdad y la pobreza enquistada en las clases asalariadas de regiones en desarrollo (ILO, IMF, et al., 2015), 2015, sino que puede fomentar una peligrosa tendencia a remunerar generosamente el capital a expensas de trabajo mal retribuido. El problema de este patrón radica en que los hogares más pobres tienen como fuente principal de ingreso las rentas laborales, quedando el grueso de las rentas del capital en manos de los hogares más ricos. Por tanto, si el capital se remunera mejor que el trabajo, se corre el riesgo de que la capacidad de consumo de los hogares más desfavorecidos se vea muy limitada mientras que la capacidad de ahorro de los hogares ricos se incrementa, lo que implicaría un aumento de la desigualdad (ILO, OECD et al., 2015).

Al analizar el resto de regiones se aprecia que las zonas con mayor peso de la remuneración del trabajo sobre el total de la huella de valor añadido son aquellas más desarrolladas como Corea, las zonas Norte y Sur de la UE, Gran Bretaña o Australia. Esto puede enmascarar dos implicaciones: o bien que la demanda final de las regiones desarrolladas se apoya principalmente en productos intensivos en trabajo (como bienes de consumo demandados por una población de 


\section{GRÁFICO 1}

\section{HUELLA DE DISTRIBUCIÓN DE LA RENTA. MODELO CON 18 REGIONES, 2011}

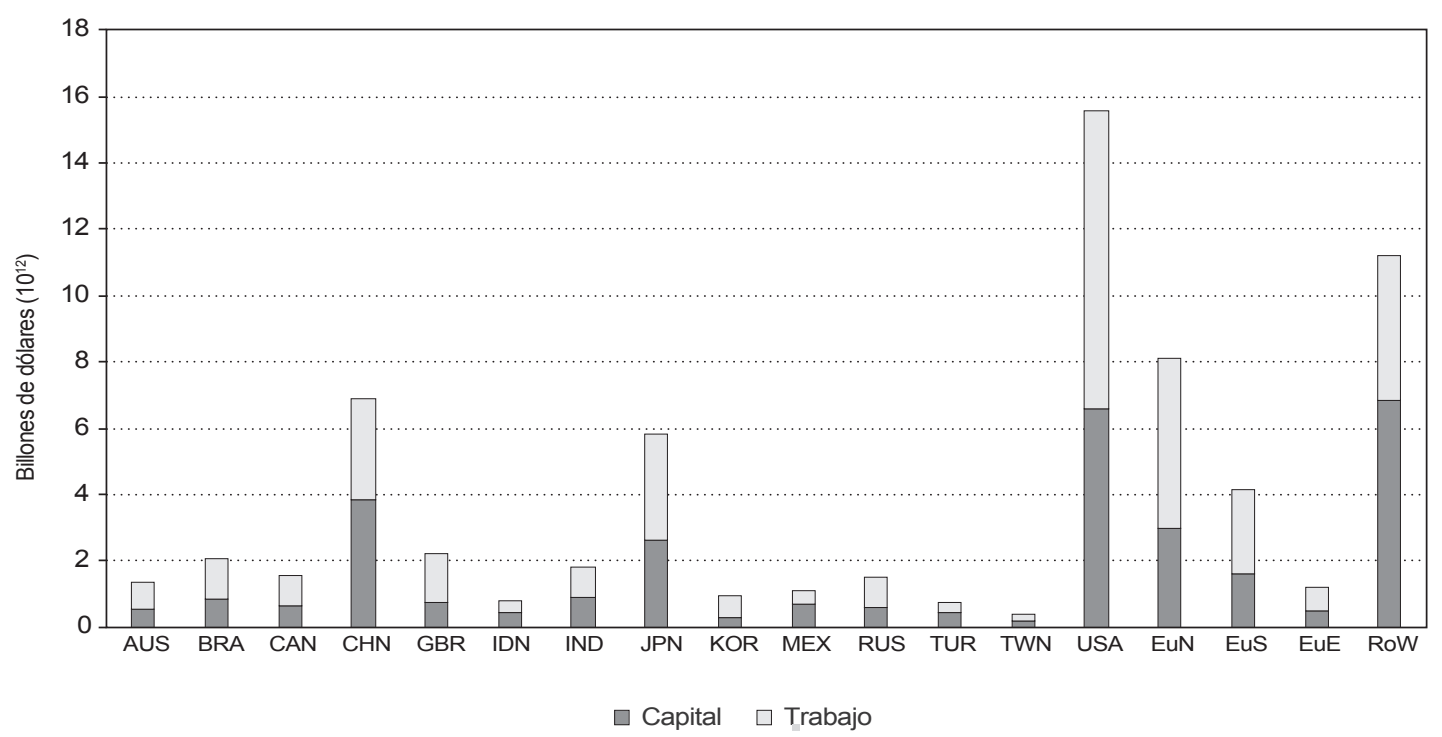

FUENTE: Elaboración propia según datos de WIOD.

elevado poder adquisitivo) o bien que el trabajo detrás de esa huella está mejor remunerado que el asociado a la huella de regiones emergentes. El Gráfico 2 muestra que más de un 80 por 100 de la huella de remuneración del trabajo de las regiones más desarrolladas es de procedencia doméstica (generada en el territorio para abastecer su propia demanda final), de modo que las rentas laborales producidas por la demanda final de estas zonas permanecen mayoritariamente en las propias regiones desarrolladas.

En definitiva, el hecho de que las regiones menos prósperas tiendan a destinar una menor porción del VA a remunerar el trabajo que las regiones más ricas (Gráfico 1) resulta preocupante. Una huella de remuneración del trabajo baja en términos relativos puede deberse a que la demanda final de las regiones en desarrollo no está contribuyendo a generar empleo o a que el empleo generado es de carácter precario y baja remuneración. Por tanto, el crecimiento económico implícito en la alta huella de capital de las regiones en desarrollo no genera las rentas laborales que se esperarían ante un crecimiento similar en regiones desarrolladas. Si paralelamente se considera que la huella de regiones desarrolladas remunera mejor el trabajo, pero ese trabajo tiene un origen principalmente doméstico (Gráfico 2), resulta evidente que las rentas transferidas a los trabajadores de países en desarrollo son escasas y probablemente insuficientes para romper la versión moderna del círculo vicioso de la pobreza propuesto por Nurkse (1953) ${ }^{6}$.

\footnotetext{
6 Los trabajadores de países pobres se ven forzados a destinar prácticamente la totalidad de sus escasas rentas al consumo, de modo que no tienen capacidad de ahorro o inversión ni expectativas de incrementar sus rentas. Las inversiones con sus consiguientes rentas del capital quedan polarizadas en una minúscula parte de la población o en manos de inversores extranjeros, de modo que la desigualdad sigue incrementándose mientras la población se ve obligada a consumir bienes producidos precisamente por mano de obra con una remuneración muy pobre, ya sea de origen doméstico o procedentes de países de similares características.
} 


\section{GRÁFICO 2}

\section{HUELLA DE REMUNERACIÓN DEL TRABAJO DE LAS REGIONES MÁS DESARROLLADAS. MODELO CON 7 REGIONES, 2011 \\ (RoW no representado)}

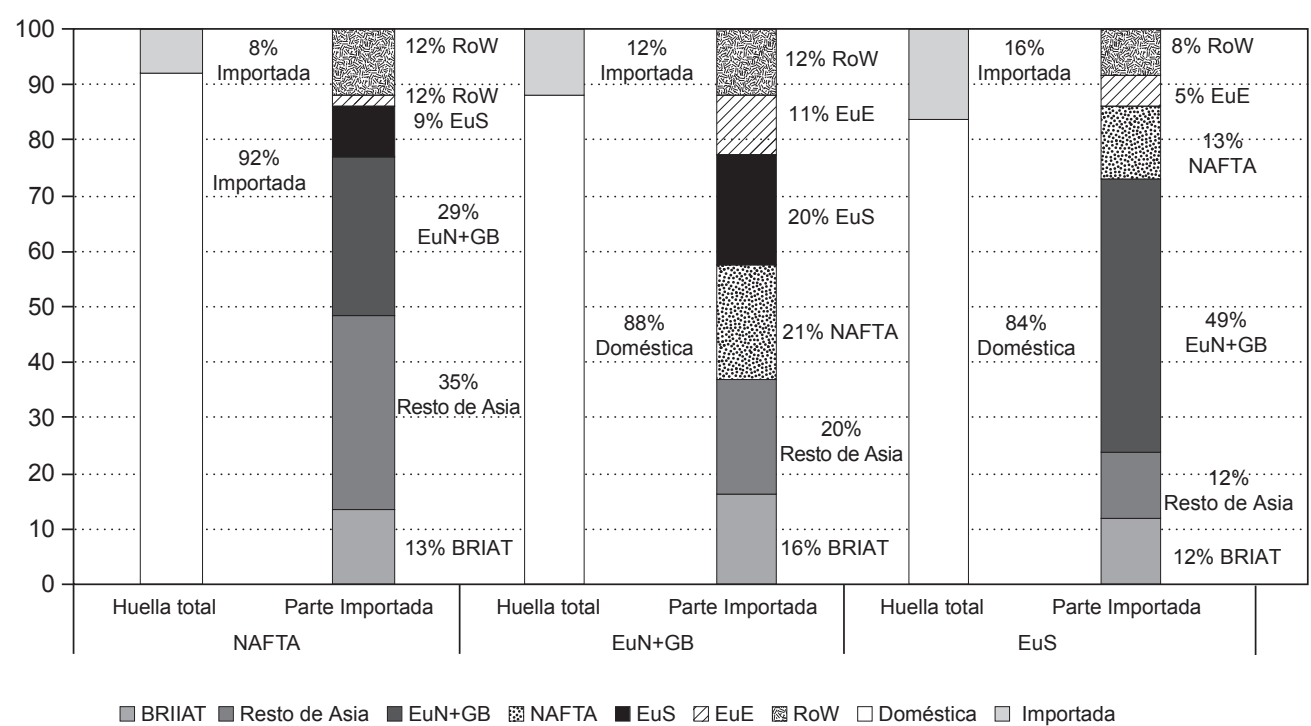

FUENTE: Elaboración propia según datos de WIOD.

De acuerdo al Gráfico 2, la parte importada de la huella de remuneración del trabajo de áreas desarrolladas aparece repartida de forma aproximadamente equitativa entre el resto de regiones, pero ello no implica necesariamente que el factor trabajo en términos físicos se importe en cantidades similares ya que la remuneración del mismo no es homogénea a nivel global. Llama la atención el claro predominio de Europa del Norte en la huella de remuneración del trabajo de Europa del Sur (lo cual no sucede en sentido inverso), previsiblemente por la elevada calidad salarial del empleo en dicha región de origen y no por unos grandes flujos de trabajo en términos físicos.

Analizando el origen de la huella de capital de las regiones menos prósperas (Gráfico 3 ) se aprecia un elevado porcentaje de origen doméstico en el resto de Asia o BRIIAT (Brasil, Rusia, India, Indonesia, Australia y Turquía) mientras que en Europa del Este un 34 por 100 de esa huella es importada principalmente de Europa del Norte. Esto exhibe la existencia de una Europa polarizada en dos niveles: Europa del Norte, zona de alto desarrollo con capacidad de inversión y altas rentas del trabajo, y Europa del Este, región en transición que demanda bienes de capital en gran medida para desarrollar un tejido productivo orientado a exportar bienes de alto valor añadido a las zonas más prósperas. Europa del Sur estaría en una situación intermedia, con un fuerte peso de rentas del norte de Europa en su huella de remuneración del trabajo.

\section{Capital humano y cualificación en el trabajo}

A continuación, se procede a analizar los indicadores incluidos en el Grupo 2 (horas de trabajo de cualificación alta, media y baja). Lo interesante de estas variables es su comparación con la distribución de rentas salariales tratada en el apartado anterior, de modo que 


\section{GRÁFICO 3}

\section{HUELLA DE REMUNERACIÓN DEL CAPITAL DE LAS REGIONES MENOS DESARROLLADAS. MODELO CON 7 REGIONES, 2011 \\ (RoW no representado)}

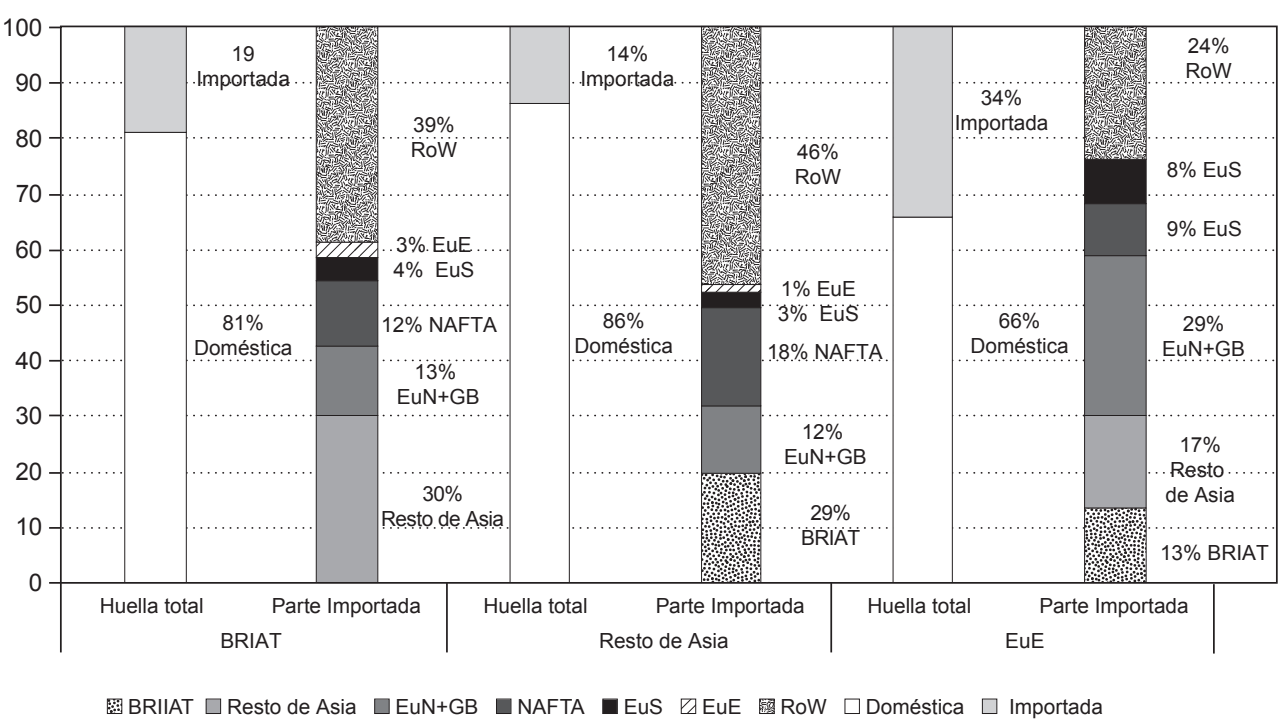

FUENTE: Elaboración propia según datos de WIOD.

se podrá determinar si hay cierta sincronía entre trabajo físico y remuneración del mismo o si, por el contrario, surgen desigualdades regionales.

El Gráfico 4 representa de forma combinada ambas magnitudes: por una parte, el mapa está sombreado de acuerdo a la remuneración del trabajo generada en la propia región (perspectiva de la responsabilidad del productor). Por otra parte, las flechas indican los flujos de trabajo físico interregionales (horas totales de trabajo de cualquier cualificación), mostrándose exclusivamente aquellos superiores a 500.000.000 de horas. El mapa revela que las rentas laborales se concentran mayoritariamente en NAFTA, seguido de Europa del Norte y del Resto de Asia, aunque considerando la elevada población de la última región en comparación con Europa del Norte esto no implica que su población tenga unas rentas per cápita acordes con las de los países más desarrollados.
Paradójicamente, los flujos en términos físicos emanan mayoritariamente del Resto de Asia y de India con destino a las regiones desarrolladas anteriormente señaladas como principales generadoras de rentas laborales. Los resultados corroboran la idea planteada por Alsamawi et al. (2014) sobre las relaciones soberano-sirviente entre países: los flujos de trabajo físico incorporado a los bienes producidos emanan de países en desarrollo (destacando China e India como indica el ranking del Cuadro A4 en el Anexo II) con destino a países desarrollados, mientras que las rentas del trabajo quedan concentradas en regiones con un alto grado de desarrollo. Ante estos resultados, la convergencia en rentas y disminución de la desigualdad pueden verse obstaculizadas (ILO, IMF et al., 2015), de modo que resulta apremiante que las instituciones revisen el papel del comercio internacional en la distribución de rentas. 


\section{GRÁFICO 4}

\section{RENTAS LABORALES GENERADAS EN EL TERRITORIO Y FLUJOS INTERREGIONALES DE TRABAJO FÍSICO, 2011}

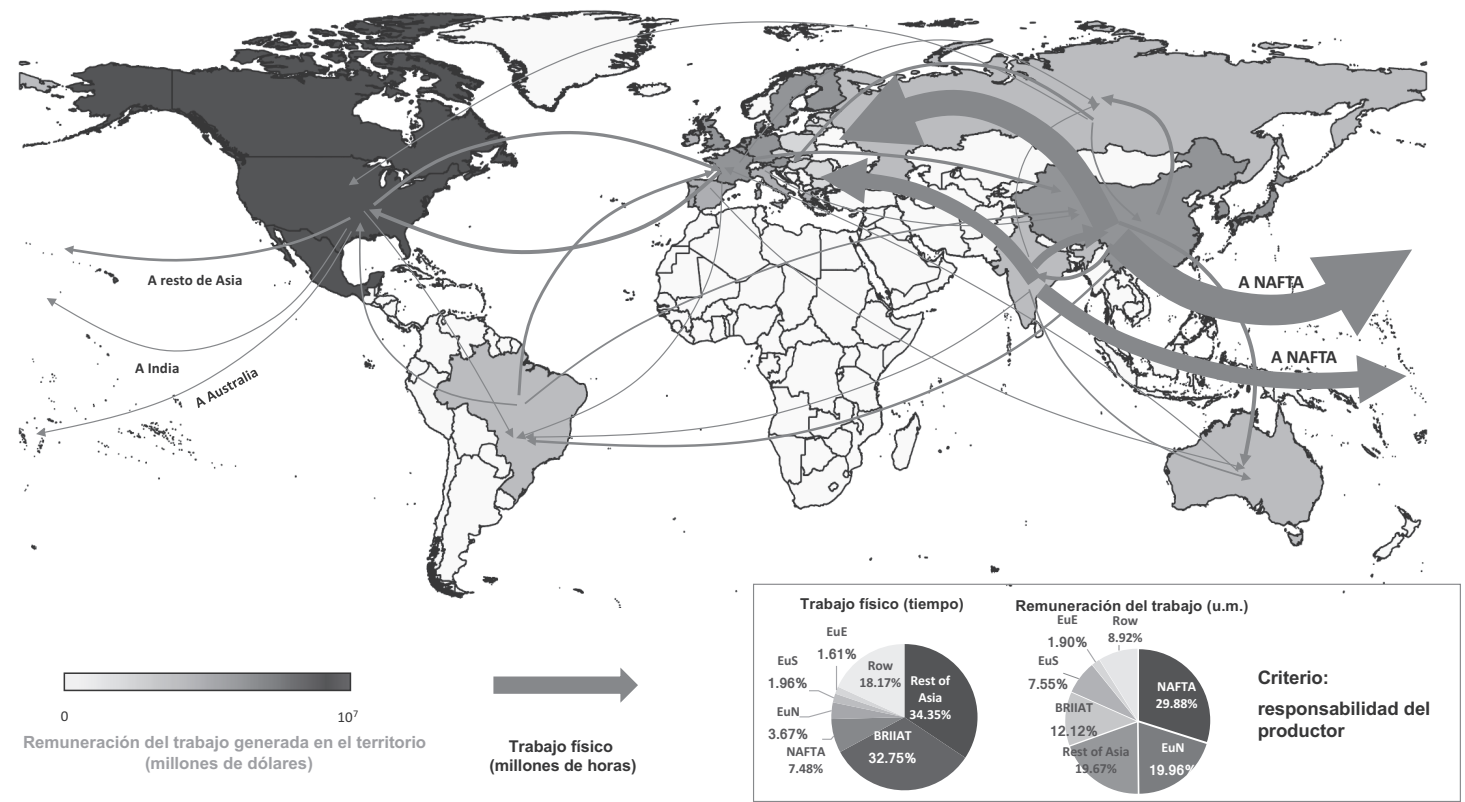

NOTAS: ${ }^{1}$ El mapa sombreado representa la remuneración del trabajo generada en el territorio. Las flechas equivalen a flujos interregionales de trabajo físico. Los gráficos circulares mostrados en la parte inferior-derecha de la figura muestran la participación como productora de trabajo físico o remuneración del trabajo de cada una de las 7 grandes regiones seleccionadas sobre el total mundial. ${ }^{2}$ La UE se representa como una única región en términos de flujos de trabajo físico para que la visualización resulte más clara. En términos de remuneración del trabajo generada en el territorio, plasmada mediante las tramas de fondo en el mapa, la UE aparece desglosada en las tres subregiones tratadas durante todo este trabajo. ${ }^{3}$ La región Resto del Mundo no se ha representado en el mapa ni en los flujos de flechas. ${ }^{4}$ Los flujos de flechas inferiores a 500.000 .000 de horas no han sido representados.

FUENTE: Elaboración propia con software de QGIS Development Team (2015) según datos de WIOD.

Siguiendo con el análisis, el Gráfico 5 muestra las tendencias regionales con el fin de aportar más información respecto a los condicionantes de la desigual remuneración del trabajo físico detectada en el Gráfico 4. En el Gráfico $5(\mathrm{~A})$, la escala de grises en el mapa refleja las horas de trabajo de alta y media cualificación por empleado, mientras que en el Gráfico 5 (B) la escala se asocia a horas de trabajo de baja cualificación por empleado, todo ello bajo la perspectiva de la responsabilidad del productor. La comparativa de ambas con el Gráfico 4 permite intuir que la mejor remuneración del trabajo en zonas desarrolladas se debe en gran medida a la mejor cualificación de los trabajadores residentes en ellas. Los trabajos precarios y con menor cualificación se encuentran deslocalizados a regiones como Asia, pero también al Sur de Europa en el caso intracomunitario. Sin embargo, el trabajo de baja cualificación está mejor remunerado en el Sur de la UE que en regiones emergentes, de modo que el problema prioritario está en los países más pobres. Este modelo de especialización en trabajo de baja calidad instaurado en regiones de bajo desarrollo limita las posibilidades de su población de recibir formación y aspirar a trabajos mejor remunerados, llegando 


\section{GRÁFICO 5}

TRABAJO FÍSICO POR EMPLEADO SEGÚN NIVEL DE CUALIFICACIÓN. REGIÓN DE ORIGEN (RESPONSABILIDAD DEL PRODUCTOR), 2011

5A. Trabajo físico de cualificación media-alta por empleado.

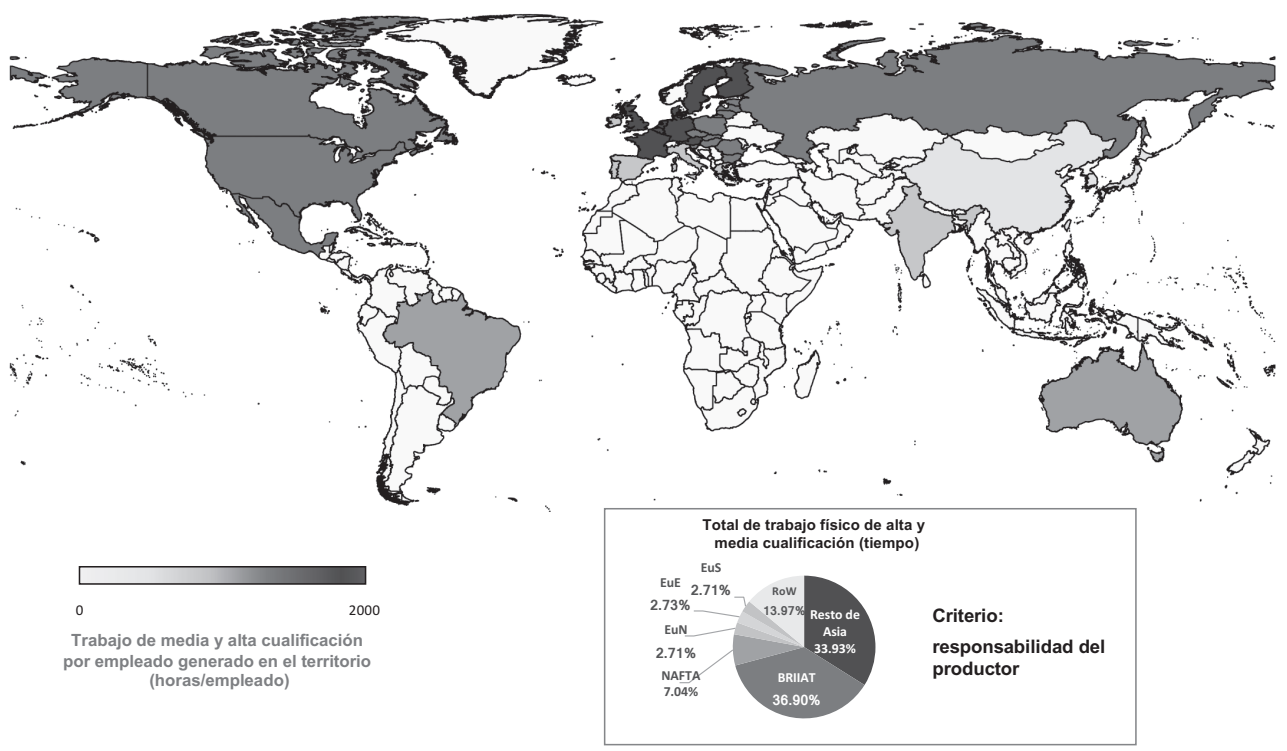

5B. Trabajo físico de cualificación baja por empleado

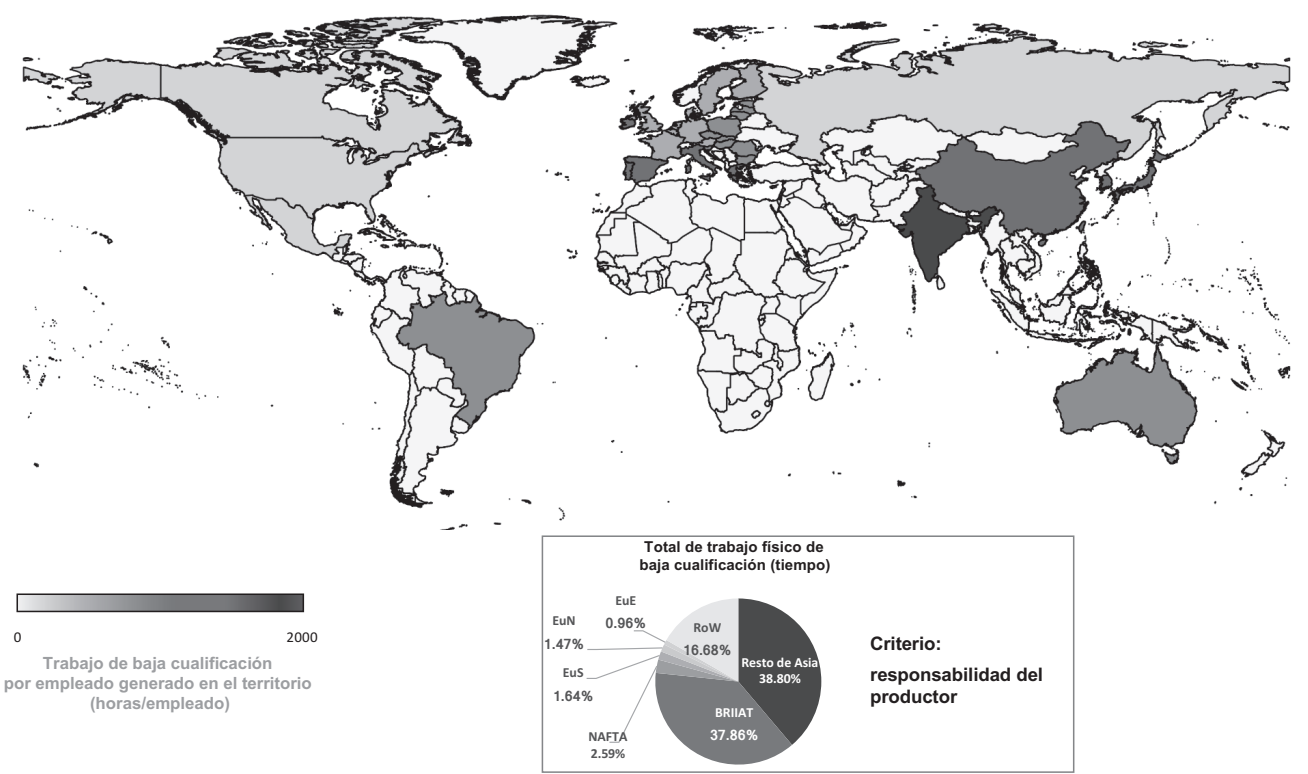

NOTAS: ${ }^{1}$ El mapa sombreado representa el trabajo físico generado en el territorio. Los gráficos circulares mostrados en la parte inferior muestran la participación como productora de trabajo físico de cada una de las 7 grandes regiones seleccionadas sobre el total mundial. ${ }^{2}$ La región Resto del Mundo no se ha considerado en la representación.

FUENTE: Elaboración propia con software de QGIS Development Team (2015)según datos de WIOD. 
incluso a generar el fenómeno conocido como pobreza intergeneracional. Los hogares pobres no disponen de recursos para proporcionar educación a sus hijos, y en muchos casos necesitan que estos comiencen a trabajar a edades tempranas para contribuir al ingreso familiar, estando esos niños abocados a la pobreza cuando sean adultos (Gómez-Paredes et al., 2016). En consecuencia, la fuerza de trabajo de estas zonas tendrá grandes obstáculos para invertir en capital humano y mejorar su situación laboral a medio-largo plazo a no ser que reciba ayuda externa.

Determinado el origen del trabajo físico por nivel de cualificación mediante el análisis desde el punto de vista del productor, resulta interesante analizar el destino de esos flujos de trabajo incorporado a los bienes demandados por cada región mediante el punto de vista del consumidor. El Gráfico 6 muestra la huella de trabajo físico (medido en horas) de 7 grandes regiones, distinguiendo tipologías de trabajo según cualificación. Las franjas sombreadas parten de cada tipología de trabajo (situadas en la parte derecha de la circunferencia) y llegan hasta las siete regiones de destino (parte izquierda de la circunferencia), de forma que la demanda final de esas regiones es la desencadenante de ese volumen de empleo. Ha de recordarse que el trabajo que conforma la huella es de carácter directo e indirecto (es decir, trabajo empleado directamente en la producción de la propia región para abastecer la demanda final doméstica, así como trabajo generado en otras regiones e incorporado a los bienes importados para cubrir dicha demanda final doméstica).

El flujo más llamativo en el Gráfico 6 es el asociado al empleo de baja cualificación, fuertemente vinculado a la demanda final de regiones emergentes como el resto de Asia o BRIIAT en las que supone más del 50 por 100 de sus respectivas huellas. Considerando que el porcentaje de remuneración del trabajo dentro de la huella de VA de regiones emergentes es inferior al de regiones desarrolladas (Gráfico 1), la causa parece ser la menor remuneración del trabajo en la huella de zonas emergentes en lugar de una menor propensión a demandar bienes intensivos en mano de obra. Regiones como el resto de Asia requieren grandes cantidades de trabajo precario (ya sea generado en el interior de la región o procedente de zonas limítrofes de características similares) para abastecer su demanda final. Si paralelamente se considera que el trabajo de baja cualificación procede a su vez de regiones en desarrollo como BRIIAT, RoW o la propia Asia (Gráfico 5), queda clara la nociva retroalimentación entre economías especializadas en trabajo mal remunerado incorporado a los bienes que consumen a causa del bajo poder adquisitivo de la población (ocasionado a su vez por las escasas rentas del trabajo percibidas por la gran mayoría de habitantes de estas regiones).

La huella de empleo de cualificación media no parece tan concentrada en esas dos grandes regiones, sino que el resto del mundo ostenta una porción importante, como es el caso de NAFTA o la zona Norte de la UE incluyendo Gran Bretaña. La huella de empleo de alta cualificación es la que presenta un reparto más semejante entre regiones, destacando el elevado flujo destinado a regiones desarrolladas como NAFTA o Europa del Norte. Dado que estas zonas son los principales generadores de este tipo de trabajo (Gráfico 5), todo apunta a que los cauces de comercio internacional hacen que los países más prósperos sean los que pueden beneficiarse de bienes producidos por empleados cualificados, originándose este tipo de empleo principalmente en el propio territorio como se reafirma en el Gráfico 7. Este tipo de bienes suelen ser de capital y con un alto componente tecnológico, de modo que su incorporación al ciclo productivo de estas regiones no hace sino incrementar aún más el diferencial de desarrollo con regiones áreas menos favorecidas cuya huella está mayoritariamente compuesta por trabajo precario incorporado a bienes de bajo VA.

En definitiva, los países desarrollados se retroalimentan consumiendo trabajo de alta cualificación procedente de socios prósperos, repartiéndose así gran parte de las rentas laborales mundiales, mientras que los emergentes consumen mayoritariamente trabajo 


\section{GRÁFICO 6}

\section{HUELLA DE HORAS DE EMPLEO POR CUALIFICACIÓN (RESPONSABILIDAD DEL CONSUMIDOR) \\ Regiones de destino. Modelo con 7 regiones, 2011}

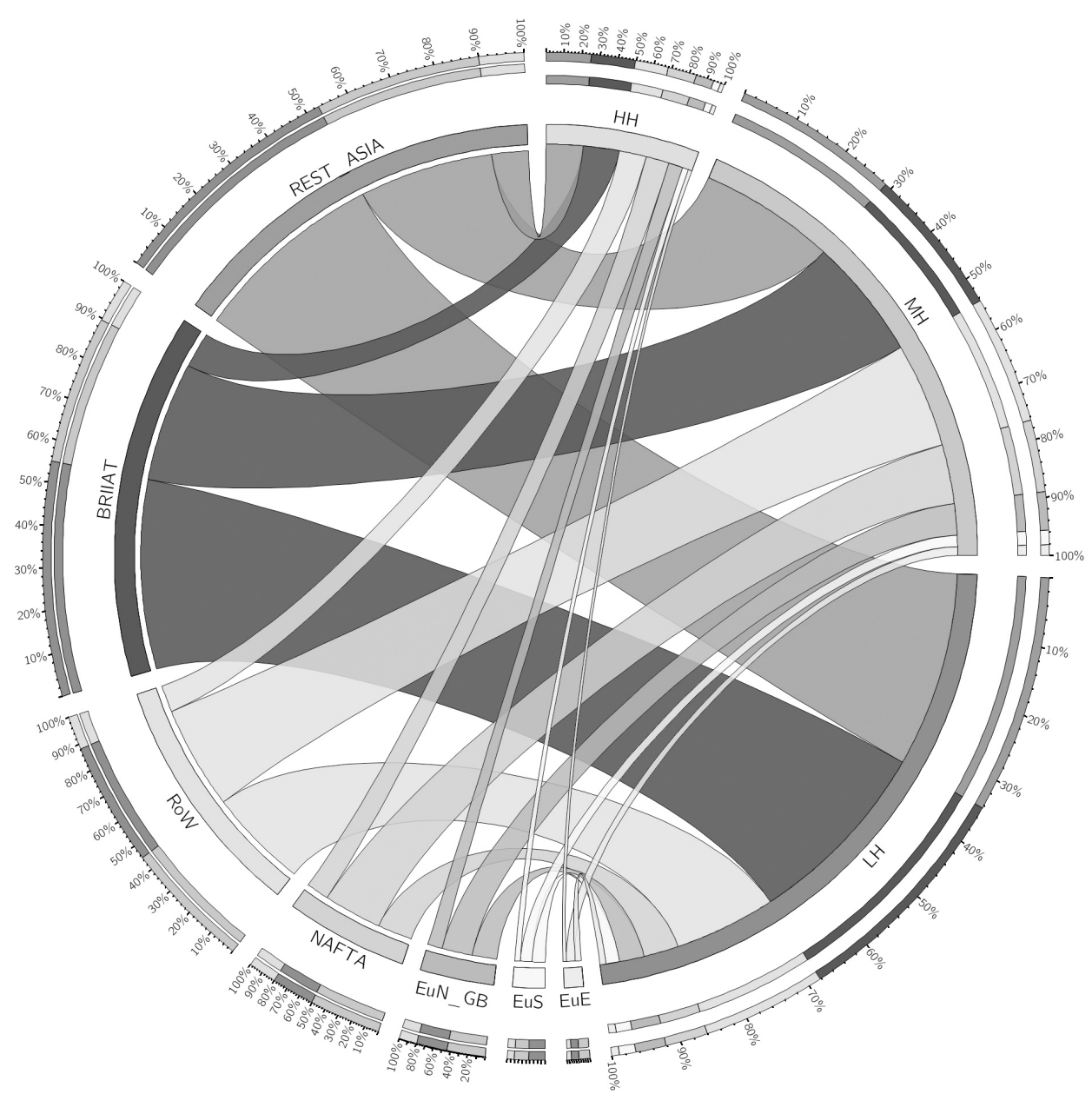

FUENTE: Elaboración propia con software de Krzywinski et al. (2009) según datos de WIOD.

precario de socios con un grado de desarrollo similar al suyo, alimentando un modelo de crecimiento sustentado en empleo de baja calidad. Como Mosley y Uno (2007) señalan, uno de los determinantes de las condiciones laborales en una cierta región es el comportamiento en materia de derechos laborales de los economías de grado semejante de desarrollo.
Centrando la atención en Europa se aprecian disparidades. El anillo exterior del Gráfico 6 muestra que la huella de Europa del Sur comprende mayoritariamente trabajo de baja cualificación, mientras que las de Europa del Norte y del Este están compuestas fundamentalmente por trabajo de media cualificación. Lo mismo sucede al evaluar la tipología de trabajo mayoritaria 


\section{GRÁFICO 7}

PORCENTAJE DOMÉSTICO EN LA HUELLA DE TRABAJO.

COMPARATIVA DE LA PERSPECTIVA MONETARIA (REMUNERACIÓN DEL TRABAJO) Y FÍSICA (HORAS DE TRABAJO TOTALES). MODELO CON 18 REGIONES, 2011

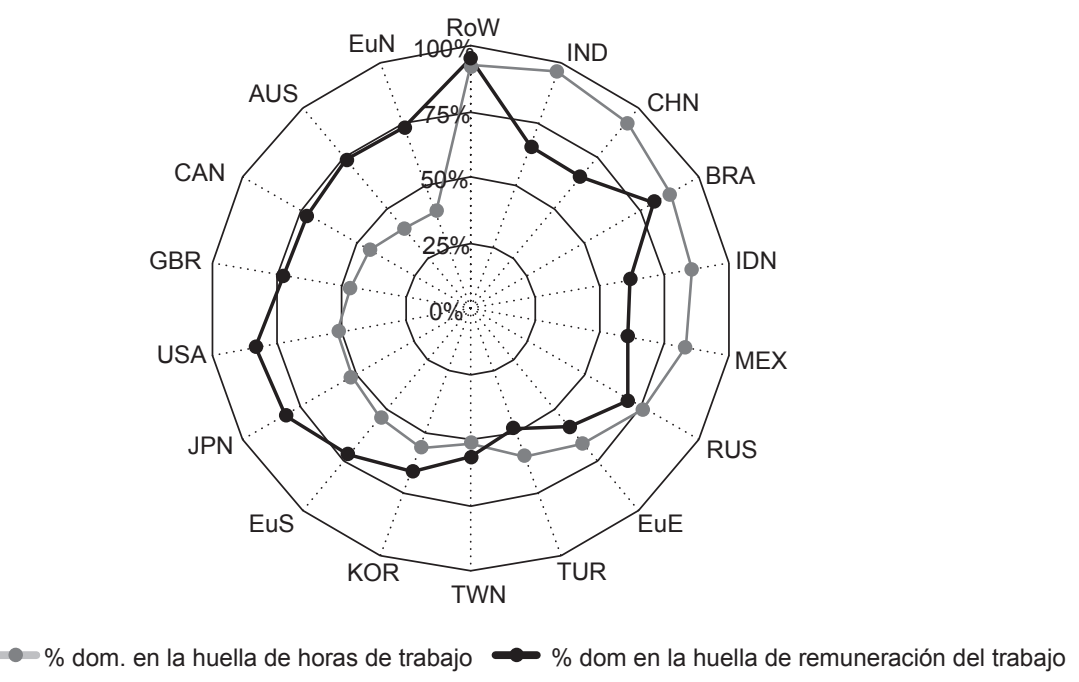

FUENTE: Elaboración propia según datos de WIOD.

generada en cada región (Gráfico 5). Esto no es sino un indicio de la polaridad intracomunitaria: el trabajo peor cualificado se concentra en economías del Sur, tradicionalmente especializadas en servicios como el turismo y con un tejido industrial menos desarrollado que el de sus vecinos del Norte y Este, lo que hace a su vez que demanden más bienes producidos con trabajo de baja cualificación que el resto de economías europeas. El trabajo de mejor cualificación se concentra en cambio en el Norte y Este de Europa, los primeros por su elevado nivel de desarrollo histórico y los segundos como consecuencia del fenómeno de deslocalización intraeuropeo de industria de contenido tecnológico medio y alto (como la de componentes electrónicos) llevado a cabo en los años noventa, del que se beneficiaron países como República Checa o Hungría (Plank y Staritz, 2013). No obstante, como se observó en el Gráfico 1 , la huella de remuneración del trabajo es mucho más elevada en el Norte que en el Este de Europa a causa del amplio consumo de bienes de procedencia doméstica (es decir, fabricados con trabajo altamente remunerado) de los países del Norte.

Siguiendo la comparativa entre remuneración del trabajo y trabajo físico con 18 regiones, en el Gráfico 7 se aprecian dos pautas claramente distintas al analizar la participación doméstica en las respectivas hueIlas: los países emergentes (parte derecha del Gráfico 7) presentan un porcentaje doméstico de la huella de trabajo físico superior al porcentaje doméstico en la huella de remuneración del trabajo, lo que indica que estas zonas demandan productos fabricados con abundante factor trabajo de la propia región, el cual está peor remunerado que el importado incorporado a los bienes producidos en otras regiones. Por el contrario, los países más desarrollados (parte izquierda del Gráfico 7) exhiben un comportamiento diametralmente 
opuesto en el que la participación del trabajo doméstico medido en horas sobre el total de su huella de trabajo físico es inferior al 50 por 100 en la mayoría de casos mientras que la participación de la remuneración laboral doméstica en la huella total de remuneración de trabajo es muy superior, especialmente en el caso de Estados Unidos y Japón. Esta observación permite concluir que las economías desarrolladas importan abundantes flujos de trabajo incorporado en los productos requeridos por su demanda final de regiones en las que la remuneración del mismo es mucho más pobre que en el caso doméstico, generándose así las relaciones soberano-sirviente propuestas por Alsamawi et al. (2014) incluso dentro de la propia Unión Europea con la diferencia de pautas entre el Norte y el Este.

\section{Conclusiones}

Indudablemente, el comercio internacional supone una vía muy poderosa para incrementar el desarrollo económico y social de los países más atrasados. En este análisis se ha comprobado que la integración de países emergentes en las redes comerciales y de producción globales implica la generación de empleo y rentas para una población numerosa y con una elevada vulnerabilidad a la exclusión económica y social, lo que obviamente es indispensable para alcanzar un desarrollo sostenible global en el que fenómenos como la pobreza o el hambre tiendan a erradicarse. Sin embargo, algunos de los resultados expuestos en este trabajo indican que actualmente las relaciones comerciales internacionales no benefician de forma equitativa a todas las regiones, de modo que su relación con otras facetas del desarrollo sostenible como la consecución de un trabajo digno a nivel mundial o la reducción de las desigualdades requeriría un análisis más profundo y acciones adicionales.

Uno de los principales problemas observados sobre la base de los resultados expuestos es la inequidad en la distribución de las rentas generadas con el comercio internacional, tanto a nivel interregional como entre los factores trabajo y capital de una misma región. Si bien es cierto que los países desarrollados destinan más del 50 por 100 del valor añadido de su huella a remunerar el trabajo, esas rentas laborales permanecen mayoritariamente en la propia región, de modo que las condiciones salariales propias de países con un alto desarrollo no parecen extenderse a países emergentes. El hecho de que las rentas se concentren en países desarrollados debido a los elevados salarios y a la mejor cualificación de la fuerza de trabajo, unido a la capacidad de su población de adquirir productos fabricados en regiones emergentes a muy bajo coste, provoca un incremento paulatino del poder adquisitivo de la población de países ricos a costa de la generación de una espiral de pobreza para el núcleo trabajador de países en desarrollo. Una hipotética convergencia de las rentas de la población asalariada a nivel mundial sería sin duda una de las claves para avanzar en la consecución de un mayor grado de desarrollo global, pero sin un papel activo de todos los agentes implicados el círculo vicioso de la pobreza seguirá su curso.

Ahondando en el importante papel que los ciudadanos de países desarrollados juegan en la inversión de estas tendencias, el consumo responsable implica la adopción de decisiones comprometidas que nada tienen que ver con el proteccionismo o boicot hacia los productos procedentes de países emergentes. La responsabilidad como consumidor pasa por demandar al sector empresarial una deslocalización justa y por exigir a las instituciones una ayuda al desarrollo efectiva y ciertas garantías sociolaborales en los acuerdos comerciales. Esa responsabilidad implica también rechazar el paradigma de consumo rápido y barato actualmente instaurado en las sociedades desarrolladas que genera la conocida como race to the bottom (Alsamawi et al., 2014) en los países de origen de esos bienes.

Al margen del papel de consumidores y productores, una inclusión honesta de países emergentes en las redes de comercio internacional requiere la intervención de instituciones internacionales para evitar 
posibles tendencias perniciosas. Considerando como algunos de los principales lastres de la población de países emergentes la falta de inversión en capital humano, de recursos financieros y de poder de negociación, la erradicación de estas carencias empoderaría a dichos ciudadanos para evitar caer en trabajos indignos y facilitaría el incremento de sus rentas laborales, mejorando así también el grado de justicia de las relaciones comerciales internacionales al acabar con el comercio de precariedad laboral incorporada a los bienes. Este estadio podría lograrse con la adecuada canalización de ayuda financiera internacional hacia la población más desfavorecida, tanto directamente a través de microcréditos, mejoras salariales, etc. como indirectamente mediante avances en materia de derechos laborales colectivos o formación profesional.

La conclusión principal de este análisis es que los patrones de comercio internacional aún distan en gran medida del marco ideal para afianzar un nivel de desarrollo sociolaboral adecuado a nivel global. Mientras el debate teórico sobre el papel del comercio internacional sigue su curso, la población de regiones emergentes recibe un regalo envenenado derivado de la integración de su país en los circuitos comerciales: un empleo con condiciones más que cuestionables cuya remuneración es claramente insuficiente, especialmente al considerar que el capital, por el contrario, se remunera en línea con la tendencia de países más avanzados. Sin embargo, tras detectar claves de vulnerabilidad de dicha población como la insuficiente retribución del trabajo, los bajos niveles de cualificación o la incapacidad de romper los círculos de pobreza, pueden establecerse pautas específicas de acción para que el crecimiento económico derivado del comercio internacional revierta positivamente en la población más desfavorecida de áreas emergentes.

\section{Referencias bibliográficas}

[1] ALSAMAWI, A., MURRAY, J. y LENZEN, M. (2014). «The Employment Footprints of Nations». Journal of Industrial Ecology, 18(1), pp. 59-70.
[2] ARCE, G. (2014). «Fuga de carbono, hipótesis refugio de emisiones e hipótesis alternativas. Una revisión de la literatura». Información Comercial Española. Revista de Economía, $\mathrm{n}^{\circ}$ 881, Tribuna de Economía. Noviembre-Diciembre, pp. 167-178.

[3] GÓMEZ-PAREDES, J.; ALSAMAWI, A.; YAMASUE, E.; OKUMURA, H.; ISHIHARA, K. N.; GESCHKE, A. y LENZEN, M. (2016). «Consuming Childhoods: An Assessment of Child Labor's Role in Indian Production and Global Consumption». Journal of Industrial Ecology, 20, 3, 611-622.

[5] GÓMEZ-PAREDES, J.; YAMASUE, E., OKUMURA, H. y ISHIHARA, K. N. (2015). "The Labour Footprint: A Framework to Assess Labour in a Complex Economy». Economic Systems Research, 27,(4), pp. 415-439.

[4] INTERNATIONAL LABOUR ORGANIZATION (2012). Global Estimate of Forced Labour. Ginebra: International Labour Organization.

[5] ILO, IMF, OECD y WB. (2015). Income Inequality and Labour Income Share in G20 Countries: Trends, Impacts and Causes. Report prepared for the G20 Labour and Employment Ministers Meeting and Joint Meeting with G20 Finance Ministers (Ankara, Turkey, 3-4 September 2015) International Labour Organization (ILO), International Monetary Fund (IMF), Organisation for Economic Co-operation and Development, The World Bank Ankara, Turkey.

[6] ILO, OECD, IMF y OECD. (2015). The Labour Share in G20 Economies. Report prepared for the G20 Employment Working Group. Antalya, Turkey, 26-27 February 2015. International Labour Organization (ILO), International Monetary Fund (IMF), Organisation for Economic Co-operation and Development, The World Bank Ankara, Turkey.

[7] IMF (2006). La integración de los países pobres en el sistema de comercio mundial. Temas de Economía 37. Washington, D.C.: International Monetary Fund.

[8] MATHWORKS, INC. (2016). MATLAB (Versión R2016a) [Software]. Englewood Cliffs, New Jersey, United States: Prentice Hall.

[9] MILANOVIC, B. (2014). «Las cifras de la desigualdad mundial en las rentas: historia y presente. Una visión general». Información Comercial Española. Revista de Economía, 880, Globalización y Desarrollo. Septiembre-Octubre, 23-38.

[10] MILLER, R. E. y BLAIR, P. D. (2009). Input-output Analysis: Foundations and Extensions (Cambridge Ed. 2nd ed.). Cambridge.

[11] MONSALVE, F.; ZAFRILLA, J. E. y CADARSO, M. Á. (2016). «Where Have all the Funds Gone? Multirregional input-output analysis of the European Agricultural Fund for Rural Development». Ecological Economics, vol. 129, 62-71.

[12] MOSLEY, L. y UNO, S. (2007). «Racing to the Bottom or Climbing to the Top? Economic Globalization and Collective Labor Rights». Comparative Political Studies, 40(8), pp. 923-948. 
[13] NURKSE, R. (1953). «The Problem of Capital Formation in Less-developed Countries». Oxford University Press, $33,1-337$.

[14] OECD (2017). El comercio internacional y el desarrollo. Recuperado 15/02/2018, de http://www.oecd.org/trade/ elcomerciointernacionalyeldesarrollo.htm

[15] PLANK, L. y STARITZ, C. (2013). «'Precarious Upgrading' in Electronics Global Production Networks in Central and Eastern Europe: The Cases of Hungary and Romania».

[16] PRELL, C., SUN, L., FENG, K. y MYRONIUK, T. W. (2015). «Inequalities in Global Trade: A Cross-Country Comparison of Trade Network Position, Economic Wealth, Pollution and Mortality». PLoS ONE, 10, 12, e0144453.

[17] QGIS DEVELOPMENT TEAM (2015). Quantum GIS Geographic Information System: Open Source Geospatial Foundation Project.

[18] RAMOS, E. y SOTA, J. (2014). «Fortalecimiento institucional y Agenda Post2015». Información Comercial Española. Revista de Economía, n 880, Globalización y Desarrollo. Septiembre-Octubre, pp. 141-149.

[19] SIMAS, M.; GOLSTEIJN, L.; HUIJBREGTS, M.; WOOD, R. y HERTWICH, E. (2014). "The 'Bad Labor' Footprint: Quantifying the Social Impacts of Globalization». Sustainability, 6(11), 7.514.

[20] SIMAS, M.; WOOD, R. y HERTWICH, E. (2015). «Labor Embodied in Trade». Journal of Industrial Ecology, 19(3), pp. 343-356.

[21] TIMMER, M. P., DIETZENBACHER, E.; LOS, B., STEHRER, R. y DE VRIES, G. J. (2015). «An Illustrated User
Guide to the World Input-Output Database: The Case of Global Automotive Production». Review of International Economics, 23(3), pp. 575-605.

[22] TIMMER, M. P.; LOS, B.; STEHRER, R. y DE VRIES, G. J. (2016). «An Anatomy of the Global Trade Slowdown Based on the WIOD 2016 Release». Groningen Growth and Development Centre (GGDC) Research Memorandum 162.

[23] NACIONES UNIDAS (2013). An Action Agenda for Sustainable Development. UN's Council of the Sustainable Development Solutions Network.

[24] NACIONES UNIDAS (2015a). Resolución 70/1 de la Asamblea General. Transformar nuestro mundo: la Agenda 2030 para el Desarrollo Sostenible. UN, Nueva York.

[25] NACIONES UNIDAS (2015b). Sustainable Development Goals. Recuperado 30 de julio de 2017, de https://sustainabledevelopment.un.org/topics/sustainabledevelopmentgoals

[26] NACIONES UNIDAS (2017). Sustainable Development. Recuperado 02/2017, 03/2014, (Último acceso: 07/04/2017), de http://www.un.org/sustainabledevelopment/

[27] VARGAS, R. y DIETZENBACHER, E. (2012). «Economies to Die for: Impacts on Human Health Embodied in Production and Trade». Unpublished Research MSc thesis, the Netherlands, University of Groningen.

[28] WIEDMANN, T. (2016). «Impacts Embodied in Global Trade Flows» Taking Stock of Industrial Ecology (pp. 159-180): Springer.

[29] WTO (2017). Entender la OMC: países en desarroIlo. Recuperado 10/03/2017, de https://www.wto.org/spanish/ thewto_s/whatis_s/tif_s/dev4_s.htm. 
ANEXO 1

\section{DESAGREGACIÓN SECTORIAL Y REGIONAL}

En este Anexo se presentan las desagregaciones regionales y sectoriales con las que se ha trabajado. Inicialmente se agregaron los datos de WIOD a 18 regiones y 14 sectores derivados de la clasificación ISIC-Rev. 3, pero también se ha trabajado de forma paralela con una agregación más compacta (agrupando las 18 regiones en 7 grandes bloques y manteniendo los 14 sectores) con el fin de representar ciertos resultados de un modo más sintético.

\section{CUADRO A1}

\section{REGIONES EMPLEADAS EN EL MODELO Y EQUIVALENCIA PROPUESTA CON REGIONES WIOD}

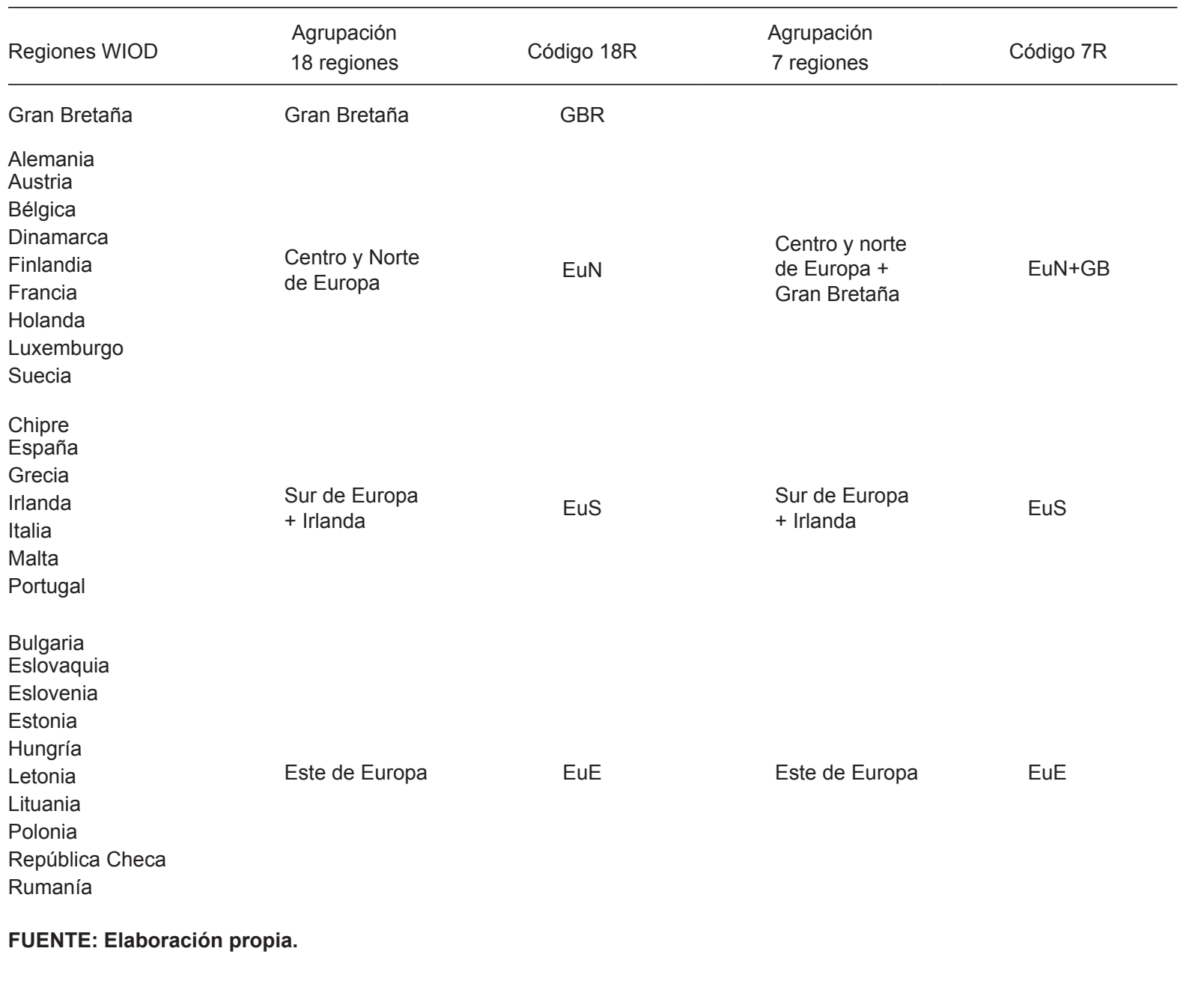


ANEXO 1 (Continuación)

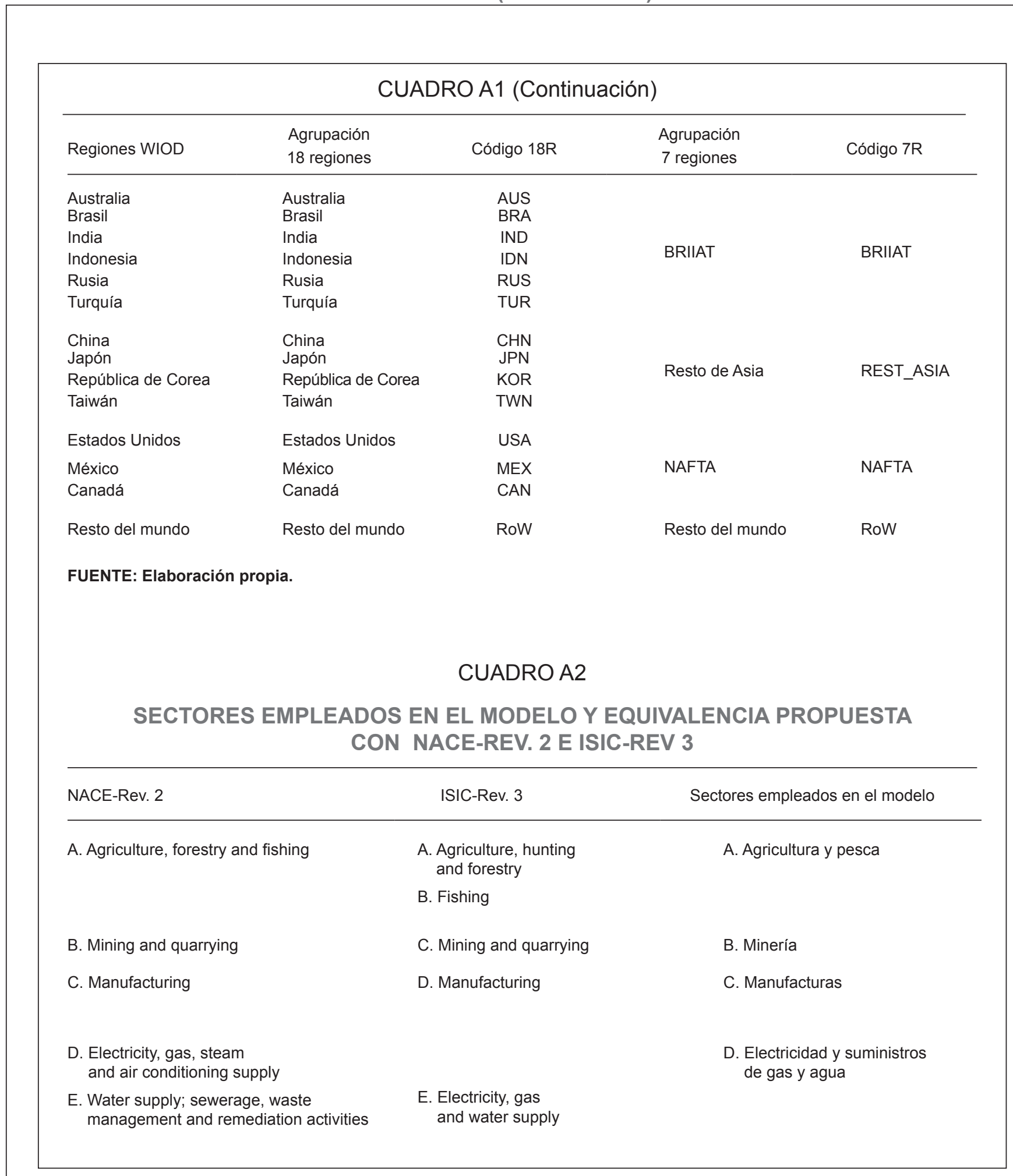


ANEXO 1 (Continuación)

\section{CUADRO A2 (Continuación)}

NACE-Rev. 2

F. Construction

G. Wholesale and retail trade; repair of motor vehicles and motorcycles

I. Accommodation and food service activities

H. Transportation and storage

J. Information and communication

K. Financial and insurance activities

L. Real estate activities

M. Professional, scientific and technical activities

N. Administrative and support service activities

O. Public administration and defence; compulsory social security

P. Education

Q. Human health and social work activities

R. Arts, entertainment and recreation

S. Other service activities

T. Activities of households as employers; undifferentiated goods- and servicesproducing activities of households for own use

U. Activities of extraterritorial organisations and bodies

NRP. Unknown activities / No response
ISIC-Rev. 3

Sectores empleados en el modelo

F. Construction (ISIC-Rev.3)

E. Construcción

G. Wholesale and retail trade; repair of motor vehicles, motorcycles and personal and household goods

$\mathrm{H}$. Hotels and restaurants

I. Transport, storage and communications

J. Financial intermediation

K. Real estate, renting and business activities

L. Public administration and defence; compulsory social security

M. Education

N. Health and social work

O. Other community, social and personal service activities

P. Activities of private households as employers and undifferentiated production activities of private households

\section{Q. Extraterritorial} organizations and bodies

X. Not elsewhere classified
F. Comercio

G. Restauración y alojamiento

H. Transporte, almacenaje y comunicaciones

I. Intermediación financiera

J. Actividades inmobiliarias y de negocios y defensa

L. Educación

M. Sanidad y trabajo social
K. Administración pública

\section{FUENTE: Elaboración propia.}


ANEXO 2

\section{RESULTADOS ADICIONALES}

Este Anexo muestra resultados adicionales que refuerzan las ideas principales planteadas en el grueso del documento. En primer lugar, se presenta una síntesis de los resultados del modelo que permite comparar responsabilidad del productor y del consumidor y analizar los elementos que componen cada una de dichas cuantías. Por otra parte, un segundo cuadro aporta información adicional útil para la comparativa internacional entre flujos de trabajo físico y flujos de remuneración del trabajo.

\begin{tabular}{|c|c|c|c|c|c|c|c|c|}
\hline \multicolumn{9}{|c|}{ CUADRO A3 } \\
\hline \multicolumn{9}{|c|}{ PRINCIPALES RESULTADOS. MODELO CON 7 REGIONES, 2011} \\
\hline & & $\mathrm{EuN}+\mathrm{GB}$ & EuS & EuE & NAFTA & BRIIAT & Resto de Asia & RoW \\
\hline \multirow{5}{*}{$\begin{array}{l}\text { CAP } \\
\text { (millones } \\
\text { de dólares) }\end{array}$} & Huella & 3.746 .961 & 1.606 .724 & 519.349 & 7.968 .743 & 3.822 .081 & 6.991 .086 & 6.856 .604 \\
\hline & $\%$ dom. & $74 \%$ & $73 \%$ & $66 \%$ & $87 \%$ & $81 \%$ & $86 \%$ & $83 \%$ \\
\hline & \% imp. & $26 \%$ & $27 \%$ & $34 \%$ & $13 \%$ & $19 \%$ & $14 \%$ & $17 \%$ \\
\hline & R. Prod. & 3.553 .536 & 1.484 .413 & 507.841 & 7.663 .258 & 3.804 .562 & 7.301.007 & 7.196.932 \\
\hline & $\%$ exp. & $22 \%$ & $21 \%$ & $33 \%$ & $9 \%$ & $19 \%$ & $17 \%$ & $21 \%$ \\
\hline \multirow{5}{*}{$\begin{array}{l}\text { LAB } \\
\text { (millones } \\
\text { de dólares) }\end{array}$} & Huella & 6.559 .602 & 2.526 .788 & 672.520 & 10.330 .282 & 4.540 .532 & 7.049 .660 & 4.375 .101 \\
\hline & \% dom. & $88 \%$ & $84 \%$ & $72 \%$ & $92 \%$ & $87 \%$ & $90 \%$ & $70 \%$ \\
\hline & \% imp. & $12 \%$ & $16 \%$ & $28 \%$ & $8 \%$ & $13 \%$ & $10 \%$ & $30 \%$ \\
\hline & R. Prod. & 7.114.312 & 2.589 .893 & 687.058 & 10.217 .586 & 4.587 .864 & 7.354 .659 & 3.503 .113 \\
\hline & $\%$ exp. & $19 \%$ & $18 \%$ & $30 \%$ & $7 \%$ & $14 \%$ & $14 \%$ & $13 \%$ \\
\hline \multirow{5}{*}{$\begin{array}{l}\mathrm{HH} \\
\text { (millones } \\
\text { de horas) }\end{array}$} & Huella & 63.235 & 25.601 & 15.002 & 101.094 & 155.972 & 159.983 & 117.464 \\
\hline & \% dom. & $78 \%$ & $79 \%$ & $85 \%$ & $87 \%$ & $95 \%$ & $93 \%$ & $85 \%$ \\
\hline & \% imp. & $22 \%$ & $21 \%$ & $15 \%$ & $13 \%$ & $5 \%$ & $7 \%$ & $15 \%$ \\
\hline & R. Prod. & 58.737 & 23.629 & 16.141 & 93.639 & 165.221 & 167.677 & 113.308 \\
\hline & $\%$ exp. & $16 \%$ & $15 \%$ & $21 \%$ & $6 \%$ & $11 \%$ & $11 \%$ & $12 \%$ \\
\hline \multirow{5}{*}{$\begin{array}{l}\text { MH } \\
\text { (millones } \\
\text { de horas) }\end{array}$} & Huella & 135.905 & 50.187 & 38.230 & 255.334 & 526.620 & 589.359 & 455.114 \\
\hline & \% dom. & $57 \%$ & $58 \%$ & $77 \%$ & $77 \%$ & $93 \%$ & $92 \%$ & $84 \%$ \\
\hline & \% imp. & $43 \%$ & $42 \%$ & $23 \%$ & $23 \%$ & $7 \%$ & $8 \%$ & $16 \%$ \\
\hline & R. Prod. & 95.232 & 35.718 & 43.574 & 211.652 & 576.615 & 638.922 & 449.038 \\
\hline & $\%$ exp. & $19 \%$ & $19 \%$ & $32 \%$ & $7 \%$ & $15 \%$ & $15 \%$ & $14 \%$ \\
\hline \multirow{5}{*}{$\begin{array}{l}\text { LH } \\
\text { (millones } \\
\text { de horas) }\end{array}$} & Huella & 108.245 & 58.074 & 26.922 & 150.692 & 831.554 & 847.183 & 439.819 \\
\hline & \% dom. & $27 \%$ & $55 \%$ & $57 \%$ & $38 \%$ & $94 \%$ & $93 \%$ & $77 \%$ \\
\hline & \% imp. & $73 \%$ & $45 \%$ & $43 \%$ & $62 \%$ & $6 \%$ & $7 \%$ & $23 \%$ \\
\hline & R. Prod. & 36.103 & 40.312 & 23.537 & 63.871 & 932.413 & 955.482 & 410.772 \\
\hline & $\%$ exp. & $19 \%$ & $21 \%$ & $35 \%$ & $10 \%$ & $16 \%$ & $18 \%$ & $17 \%$ \\
\hline
\end{tabular}


ANEXO 2 (Continuación)

\begin{tabular}{|c|c|c|c|c|c|c|c|}
\hline \multicolumn{8}{|c|}{$\begin{array}{c}\text { RANKING DE FLUJOS NO DOMÉSTICOS DE TRABAJO FÍSICO Y RENUMERACIÓN } \\
\text { DEL TRABAJO. MODELO CON } 18 \text { REGIONES, } 2011\end{array}$} \\
\hline \multicolumn{4}{|c|}{ Ranking de flujos interregionales en millones de horas } & \multicolumn{4}{|c|}{ Ranking de flujos interregionales en millones de dólares } \\
\hline Puesto & $\begin{array}{l}\text { Origen (región en la } \\
\text { que se desarrolla } \\
\quad \text { el trabajo) }\end{array}$ & $\begin{array}{l}\text { Destino de } \\
\text { los productos } \\
\text { generados }\end{array}$ & $\begin{array}{l}\text { Flujo } \\
\text { (millones } \\
\text { de horas) }\end{array}$ & Puesto & $\begin{array}{l}\text { Origen (región } \\
\text { receptora de } \\
\text { rentas laborales) }\end{array}$ & $\begin{array}{l}\text { Destino de } \\
\text { los productos } \\
\text { generados }\end{array}$ & $\begin{array}{c}\text { Flujo } \\
\text { (millones \$) }\end{array}$ \\
\hline 1 & $\mathrm{CHN}$ & USA & 63.672 & 1 & EuN & Eus & 163.070 \\
\hline 2 & $\mathrm{CHN}$ & EuN & 40.901 & 2 & EuN & USA & 140.736 \\
\hline 3 & IND & USA & 36.492 & 3 & EuS & EuN & 127.078 \\
\hline 4 & $\mathrm{CHN}$ & JPN & 27.871 & 4 & $\mathrm{CHN}$ & USA & 124.314 \\
\hline 5 & IND & EuN & 20.789 & 5 & EuN & $\mathrm{CHN}$ & 109.246 \\
\hline 6 & $\mathrm{CHN}$ & EuS & 15.022 & 6 & CAN & USA & 108.495 \\
\hline 7 & IND & $\mathrm{CHN}$ & 13.390 & 7 & USA & EuN & 104.811 \\
\hline 8 & $\mathrm{CHN}$ & KOR & 12.018 & 8 & EuN & GBR & 97.322 \\
\hline 9 & $\mathrm{CHN}$ & IND & 11.730 & 9 & GBR & EuN & 91.775 \\
\hline 10 & $\mathrm{CHN}$ & AUS & 11.349 & 10 & USA & CAN & 87.141 \\
\hline \multicolumn{8}{|c|}{$\begin{array}{l}\text { NOTAS: }{ }^{1} \text { Row se encuentra excluído del ranking. }{ }^{2} \text { Se han excluido de la clasificación los flujos intrarregionales. Consultar } \\
\text { abreviaturas empleadas para denotar las regiones en el Cuadro A1 (Anexo I). } \\
\text { FUENTE: Elaboración propia según datos de WIOD. }\end{array}$} \\
\hline
\end{tabular}

